\title{
Single Input LC Series Resonant Converter Based High Brightness Light Emitting Diode Driver with ZVS
}

\author{
Ramanjaneya Reddy Udumula ${ }^{1, \otimes}$ \\ ${ }^{1}$ SRM University, Andhra Pradesh \\ $\otimes_{\text {urreddy89@gmail.com }}$
}

\begin{abstract}
This work proposes a high brightness light emitting diode (HBLED) driver circuit based on a full-bridge LC series resonant converter with series DC bus for low power applications with a dimming feature. The proposed configuration consists of fullbridge LC series resonant converter with a series DC bus. The idea behind the concept is to supply the light emitting diode (LED) threshold voltage directly from the constant DC bus and the control voltage, which is used for current regulation, is supplied through a full-bridge LC resonant converter. Since the control voltage responsible for current regulation is only processed by the full-bridge series resonant converter, the conduction loss is less even if several LED strings are connected to the same converter. The proposed HB-LED driver is characterized by low switching loss, reduced component count, high efficiency, and reduction of output electrolytic capacitor. Further, double pulse width modulation (DPWM) dimming control is designed and used to control the average output currents. The proposed high brightness light emitting diode (HB-LED) driver circuit based on a full-bridge LC series resonant converter is simulated using Orcad/PSpice software. The theoretical anal$y$ sis and predictions of the proposed full-bridge series resonant converter-based HB-LED driver is in close agreement with the results obtained.
\end{abstract}

Keywords: Light Emitting Diodes, LC resonant converter, PWM diming, zero voltage switching (ZVS), Centre tapped transformer.

\section{Introduction}

Globally, one fifth of electrical energy goes on lighting. Hence the drive for efficient, reliable lighting systems. In virtue of their superior longevity, compactness, excellent light efficacy per watt, eco-friendly nature, and color rendering, light emitting diodes (LEDs) are replacing conventional light sources in residential, streetlights, automotive and decorative lighting applications [1]; [2]; [3]; [4]; [5].

Since the forward current of LED alters the illumi- nation level of the light bulb, it needs to be regulated precisely. LEDs can be powered with either linear voltage regulators (LVR) or switched mode regulators (SMPS). Nevertheless, SMPS are more commonly used power supplies owing to compactness and high efficiency. In literature, several types of converter configurations such as buck, boost and buck-boost converters are proposed, however when these converters used for the for LED lighting systems resulted in a trade-off between size of reactive component and efficiency [6]; [7]. Therefore, there is a need for an efficient LED driver circuit that can perform the same task with more efficiency and durability by implementation of latest converter topologies [8]; [9]; [10]; [11].

High brightness LEDs are currently used by manufacturing firms to design lamp units. In order to amplify light intensity, multiple numbers of LEDs are stacked together in series and parallel combination as per the load requirement. The intensity of light and chromaticity straight away depend on the forward current passing through the LED; therefore, it is desirable to drive LED load with constant current [12]; [13]; [14]; [15]; [16]; [17]; [18]; [19]. The idea is to use two sources, one to supply threshold voltage directly, the other source being the full-bridge LC series resonant converter, which regulates the LED current. It results in improved efficiency and high reliability [20]; [21]. Fig. 1 (a) and fig. 1(b) illustrate the LED equivalent model and concept of the proposed work, respectively.

This concept was executed by using buck, boost, and buck-boost converters as the current regulator for a low power application. However, for high power applications the use of buck, boost, and buck-boost regulators is limited, since increasing load results in a reduction in switching frequency, resulting in bulky reactive components. Further, it is difficult to get zero voltage switching, and lifespan is limited due to the presence of electrolytic capacitors at load terminals. The flyback converter can be used for low power applications; however, it is not advisable to use this con- 


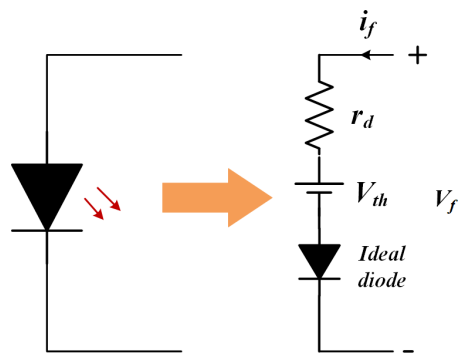

(a)

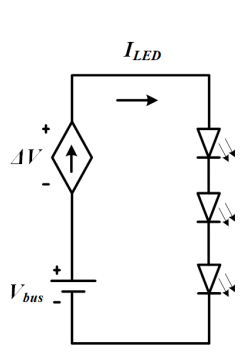

(b)

Figure 1: (a) Equivalent model of LED; (b) Concept of proposed work

verter for output power above $60-70 \mathrm{~W}$, as it requires a large transformer which in turn reduces overall efficiency. Dimming control is often needed to control the illumination level of LED light for the human need to create a comfortable environment. Moreover, dimming operations result in reduced power consumption and produce less heat hence increasing LED lifespan and optimizing running costs. Therefore, dimming control is essential in LED lighting applications. The illumination of LED is directly related to its average current. Therefore, dimming control techniques such as amplitude modulation (AM), pulse width modulation (PWM), hybrid AM/PWM technique, integral control and double PWM control are used to regulate the average output current. These control methods have their own merits and demerits. This work uses the two-source concept of driving LEDs; one is to supply cut-in voltage which is directly supplied through the $\mathrm{dc}$ bus and other is the regulating voltage supplied to the load through a full-bridge series resonant converter as current regulator. The proposed converter has several benefits such as reduced component count, compact size, and reduction of electrolytic capacitors, whereas zero voltage switching results in improved efficiency. The dimming feature was achieved by using double pulse width modulation control.

\section{Circuit Configuration and Op- eration}

The proposed converter configuration is illustrated in fig. 2. The bus voltage $\left(V_{\text {bus }}\right)$ can be obtained through either an AC grid by using an AC-DC converter along with a filter or a battery source. A fullbridge LC series resonant converter, operating as a current regulator, is placed between the LED load and the dc voltage bus. The power to the LED load is supplied through a full-bridge LC resonant converter along with the $\mathrm{dc}$ bus, rather than through a resonant converter alone.

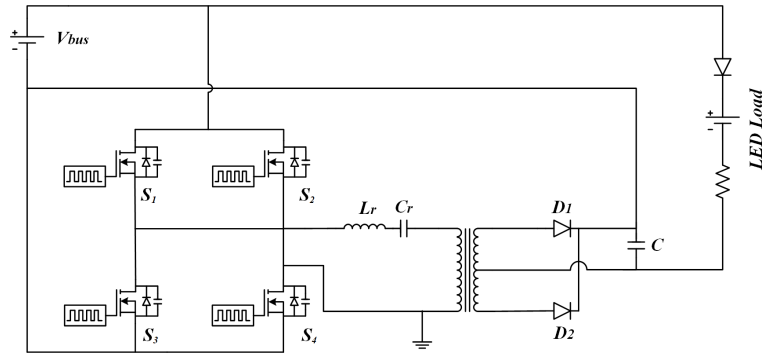

Figure 2: Proposed full-bridge LC series resonant converter

The LC series resonant converter consists of a tank circuit supplied through a full-bridge inverter. A capacitor is connected at the end of the converter output for filtering purposes. This regulating voltage $(V c)$ from the LC series resonant converter is added along with the bus voltage and supplied to the LED load. The cut-in voltage is supplied directly through bus voltage $\left(V_{\text {bus }}\right)$ and the forward regulating current is supplied through the full-bridge LC resonant converter. This regulating current is controlled by using double pulse width modulation control. The voltage supplied by the full-bridge LC series resonant converter is very low compared to the cut-in voltage supplied directly through bus voltage. Hence, switching losses can be greatly reduced on each component, ensuring high power efficiency.

The resonant frequency of the full-bridge LC circuit is decided by the values of the resonant inductor $\left(L_{r}\right)$ and capacitor $\left(C_{r}\right)$ present in the tank circuit. Zerovoltage-switching (ZVS) and zero-current-switching (ZCS) can be decided by resonant frequency $\left(f_{o}\right)$ if the switching frequency $\left(f_{s}\right)$ is higher than resonant frequency $\left(f_{o}\right)$ ZVS can be achieved, and the switching frequency is lesser than resonant frequency ZCS can be achieved. A resonant capacitor $\left(C_{r}\right)$ is added in the circuit to negotiate the impedance effect caused against the power flow due to parasitic inductance and supplying voltage with a frequency closer to resonant frequency to the tank circuit.

\subsection{Operating modes}

Analysis of the circuit is simple, as the circuit is divided into two major parts. The primary part is the bus voltage $\left(V_{\text {bus }}\right)$, which supplies the majority of the voltage to the load, satisfying the forward voltage drop of the LED load. The second part is the full-bridge LC series resonant converter, which supplies the control voltage, regulating the LED output current $\left(I_{o}\right)$. The resonant converter output $\left(V_{c}\right)$ is connected in series with the bus voltage as shown in fig. 3 .

The full-bridge LC series resonant converter use controlled switches to generate a square wave voltage in- 


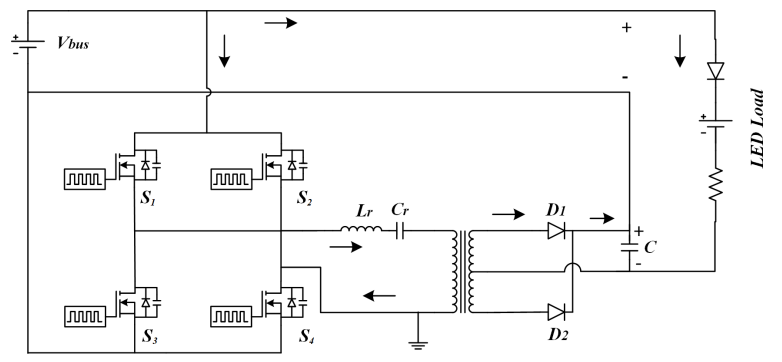

Figure 3: Proposed circuit topology

put for the filter for tank current $\left(i_{L}\right)$, formed by the series combination of resonant inductor $\left(L_{r}\right)$ and resonant capacitor $\left(C_{r}\right)$. The resonant inductor current $\left(i_{L}\right)$ oscillates and is rectified and filtered to produce dc capacitor output voltage $\left(V_{c}\right)$. The working of the converter is based on the relation between the resonant frequency of the filter and switching frequency and gives nearly sinusoidal current $\left(i_{L}\right)$ which is oscillating in nature and has a frequency almost equal to switching frequency when the switching frequency is maintained closer to the resonant frequency of the filter.

Fig. 4 illustrates the square wave input voltage $\left(V_{a}\right)$ to the filter, the current $i_{L}$, the switch current $i_{s 1}$ and the input to the centre tapped rectifier $V_{b}$. The square wave voltage $\left(V_{a}\right)$ is the inverted waveform of bus voltage $\left(V_{\text {bus }}\right)$. The capacitor voltage $\left(V_{c}\right)$ is the rectified form of $V_{b}$ when $i_{L}$ is positive and $-V_{c}$ when $i_{L}$ is negative. The output voltage of the converter is assumed to be constant because of the rectifier diode configuration.

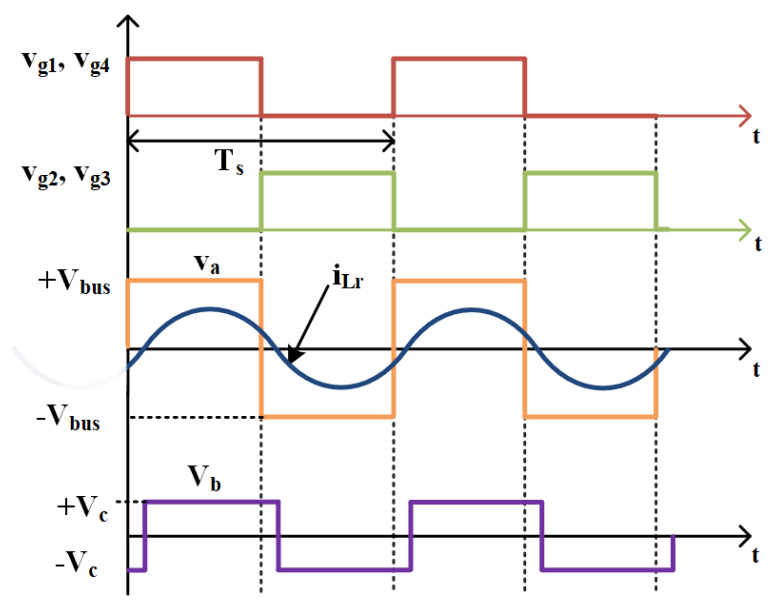

Figure 4: Voltage and current waveforms for $w_{s}>w_{0}$

The proposed full-bridge LC resonant converter is analyzed by considering the fundamental components of the voltages and currents. The $A C$ equivalent circuit is as shown in fig. 5. The peak value of the fundamental frequencies of the square waves $V_{a}$ and $V_{b}$ are

$$
\begin{gathered}
V_{a 1}=\frac{4 \cdot V_{b u s}}{\pi} \\
V_{a 1}=\frac{4 \cdot V_{c}}{\pi}
\end{gathered}
$$

The LC resonant tank voltage and currents are given by

$$
\begin{gathered}
V_{r}(t)= \begin{cases}+V_{\text {bus }}, & 0<t<\delta T s \\
-V_{\text {bus }}, & \delta T s<t<T s\end{cases} \\
I_{r}(t)=I_{L}(t) \sin (t+\phi)
\end{gathered}
$$

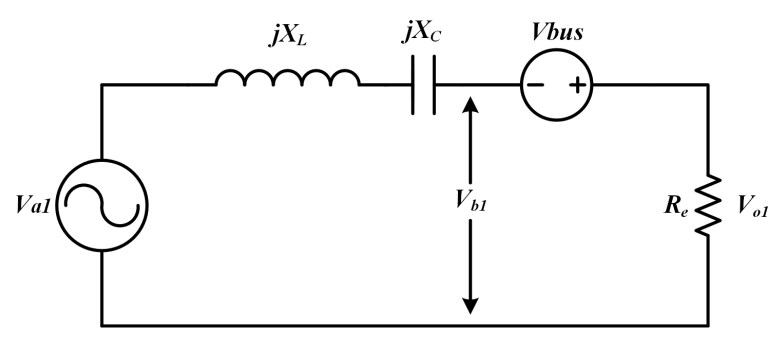

Figure 5: Equivalent circuit of proposed converter

From fig. 5 we have,

$$
V_{o 1}=V_{b 1}+V_{b u s}
$$

The LED lamp is represented by a forward cut-in voltage $V_{F}$ in series with its dynamic resistance $r_{d}$. The voltage across the LED lamp can be represented as

$$
V_{L E D}=V_{r}+I_{L E D} r_{d}
$$

Here, $I_{L E D}$ is the current flowing through the LED lap which is the average of full wave rectified transformer secondary current $i_{b}$.

$$
I_{L E D}=I_{a}=I_{b}=\frac{2 \cdot L_{1}}{\pi}
$$

The effective load resistance of the resonant converter can be obtained from eqn. 2 and eqn. 7

$$
R_{e}=m^{2} V_{b 1} / I_{L 1}=8 m^{2} / \pi^{2} R_{L}
$$

where $m$ is the transformer turns ratio $\left(m=N_{p} / N_{s}\right)$. 
To find the relation between $V_{\text {bus }}$ and $V_{o}$, remove $V_{\text {bus }}$ from fig. 5 as shown in fig. 6 .

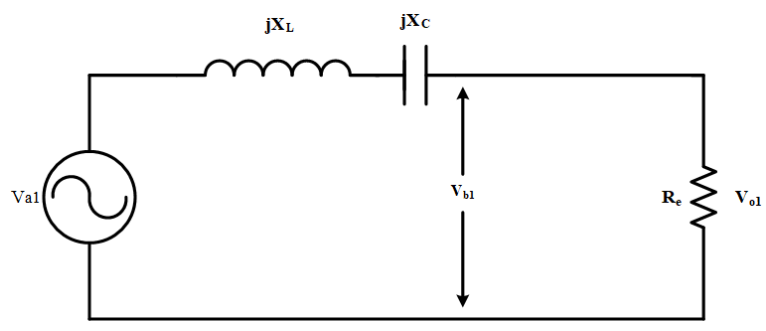

Figure 6: Equivalent circuit of proposed converter excluding $V_{\text {bus }}$

By simplifying eqn. 1 and eqn. 2 the output voltage can be expressed as

$$
V_{0}=V_{\text {bus }}\left(\frac{1}{1+\left(\frac{X_{L}-X_{C}}{R_{e}}\right)^{2}}\right)
$$

where,

$$
\begin{gathered}
X_{L}=\omega_{s} L_{r} \\
X_{C}=\frac{1}{\omega_{s} C_{r}}
\end{gathered}
$$

From the above eqn. 9, eqn. 10 and eqn. 11 it is clear that the switching frequency has a major impact on the output voltage and its sensitivity. Further, the quality factor of the resonant converter is denoted by $\mathrm{Q}$ and is expressed as follows

$$
Q=\frac{\omega_{S} L_{r}}{R_{e}}=\frac{1}{\omega_{s} R_{e} C_{r}}
$$

By substituting eqn. 10, eqn. 11 and eqn. 12 into eqn. 9 the gain $\left(V_{o} / V_{\text {bus }}\right)$ can be expressed as follows

$$
\frac{V_{0}}{V_{\text {bus }}}=\frac{1}{\left(1+Q^{2}\left[\frac{\omega}{\omega_{0}}-\frac{\omega_{0}}{\omega}\right]^{2}\right)}
$$

The gain $\left(V_{o} / V_{\text {bus }}\right)$ versus normalized frequency $\left(\omega_{\mathrm{s}} / \omega_{\mathrm{o}}\right)$ is plotted with $\mathrm{Q}$ as the parameter is illustrated in fig. 7. Since $i_{L r}$ has more of a sinusoidal quantity for the above resonance, the curves are more accurate in these frequencies.

\subsection{Design of Resonant Converter}

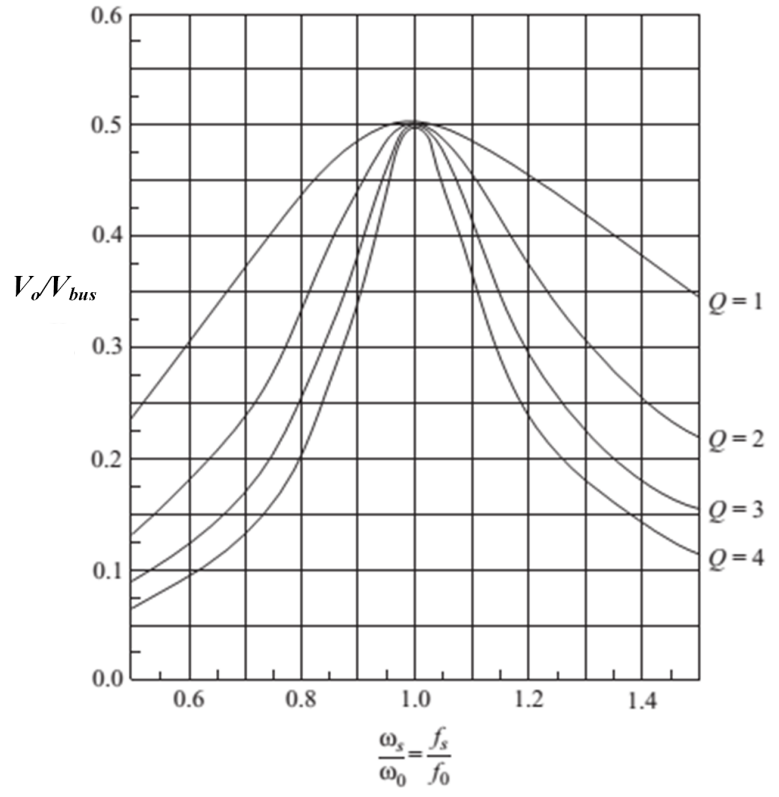

Figure 7: Normalized Frequency Response

The values for the components in the series resonant converter are given by the following calculations. The value of effective load resistance can be expressed as

$$
R_{e}=\frac{8 m^{2}}{\pi^{2} R_{L}}
$$

The quality factor $Q$ can be expressed as

$$
Q=\frac{1}{2 \pi f_{o} R_{e} C_{r}}
$$

By substituting the value of $Q$ in eqn. 13 can be expressed as follows

$f_{0}^{2}-\left[f_{s}^{2} R_{s} C_{r}\left(V_{\text {bus }} / V_{0}\right)-1\right] f_{0}^{3}-\left(2 f_{s}^{2}\right) f_{0}^{2}+f_{0}^{4}=0$

By simplifying the $4^{\text {th }}$ order equation, we can obtain the value of the resonant frequency $\left(f_{o}\right)$ and by substituting this value in eqn. 15 for an assumed resonant capacitor value such as $C_{r}=0.1 \mu \mathrm{F}$ we can obtain the value of the quality factor, which is useful in finding $\left(L_{r}\right)$ as $L_{r}=\frac{Q R_{e}}{2 \pi f_{o}}(17)$ Where $\mathrm{Q}$ is the quality factor of the converter, $R_{e}$ is the effective load resistance, $f_{o}$ is the resonant frequency and $f_{s}$ is the switching frequency.

\subsection{Dimming Control}

Dimming control is often needed to control the illumination level of LED light for the human need to create a comfortable environment. Moreover, since dimming 


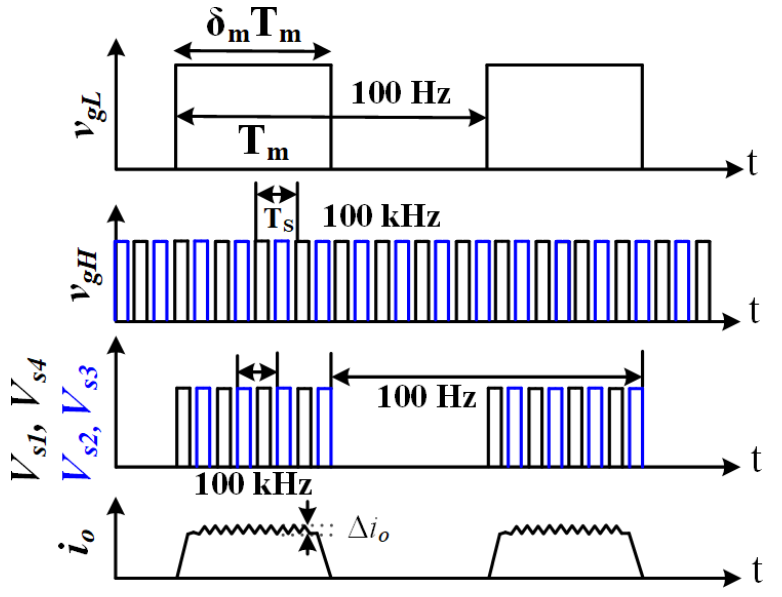

Figure 8: Double pulse width modulation dimming waveforms

operations result in reduced power consumption and produce less heat, they increase the LED lifespan and optimize the running cost. Therefore, dimming control is essential in LED lighting applications. The illumination of LED is directly related to average current. In this proposed work a double pulse width modulation (DPWM) dimming control technique is adopted to control the illumination level of LED light, as illustrated in figure. 8. With DPWM control when the low-frequency pulse signal $\left(v_{g L}\right)$ is high, the converter operates with high-frequency pulse. Consequently, when $v_{g L}$ is low, the converter is shut down for a long duration. In fig. $8, T_{m}$ and $\delta_{m}$ are the switching period and duty cycle of the low frequency dimming signal, respectively. By varying $\delta_{m}$ from $20 \%$ to $100 \%$, ZVS operation is achieved and illumination of LED light is adjusted by controlling the average output current.

\section{SIMULATION RESULTS AND ANALYSIS}

Orcad/PSpice simulation environment is used to simulate and perform detailed analysis of the proposed circuit topology based on a full-bridge LC series resonant converter with series DC bus in fig. 2. Table 1 illustrates the specifications and design parameters used for simulation analysis.

A $24 \mathrm{~V} \mathrm{DC}$ source is utilized for input voltage source and load is modeled with 9 LEDs connected in series; each LED is impressed by $3.6 \mathrm{~V}$ and carries a current of $600 \mathrm{~mA}$. The calculated value of effective load resistance from equation 14 is $R_{e}=12.98$. For a selected value of resonant capacitor $C_{r}=0.1 \mu \mathrm{F}$ and input dc bus voltage of $24 \mathrm{~V}$, the value of resonant frequency can be calculated from equation 16 as $f_{o}=$ 58.6 KHz. From equations 15, 16 and 17 we can obtain values of quality factor $\mathrm{Q}=2.1$ and the resonant inductor value is $L_{r}=74 \mu \mathrm{H}$. The Orcad/PSpice
Table 1: Parameters used in simulation of proposed converter

\begin{tabular}{c|c}
\hline Parameter & Rating \\
\hline \hline$V_{\text {bus }}$ & $24 \mathrm{~V}$ \\
$I_{O}$ & $600 \mathrm{~mA}$ \\
$P_{O}$ & $20 \mathrm{~W}$ \\
$f_{s}$ & $100 \mathrm{kHz}$ \\
$L_{r}$ & $74 \mu \mathrm{H}$ \\
$C_{r}$ & $0.1 \mu \mathrm{F}$ \\
$C_{o}$ & $50 \mu \mathrm{F}$ \\
\hline \hline
\end{tabular}

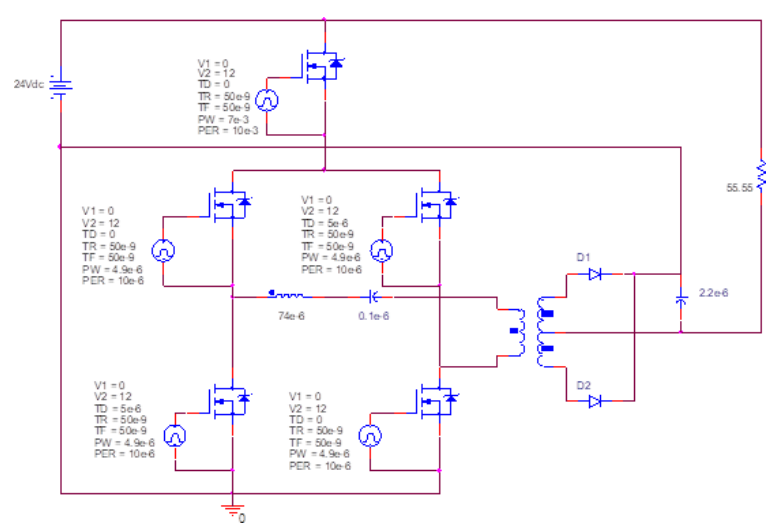

Figure 9: Simulation circuit of proposed converter topology

simulation circuit is illustrated in fig. 9. This circuit was simulated with the values given in table I. The full-bridge inverter output voltage $\left(V_{a b}\right)$ and resonant inductor current are illustrated in fig. 10. The converter is designed with switching frequency higher than the resonant frequency, which resulted in zero voltage switching of proposed converter topology.

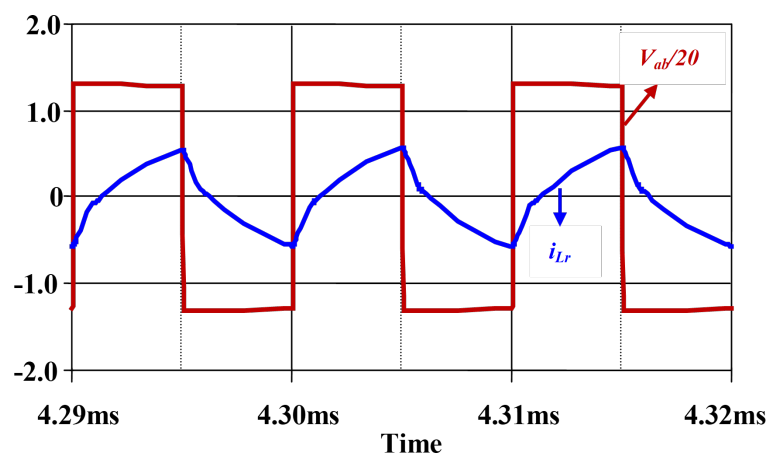

Figure 10: Simulation waveforms of inverter output voltage and resonant inductor current $\left(i_{L r}\right)$

The gate to source voltage $\left(V_{g s}\right)$, drain to source voltage $\left(V_{d s}\right)$ and drain current $\left(i_{d}\right)$ are illustrated in fig. 11. From fig. 11 it is clear that the switch is turning on and turning off at zero voltage switching, 


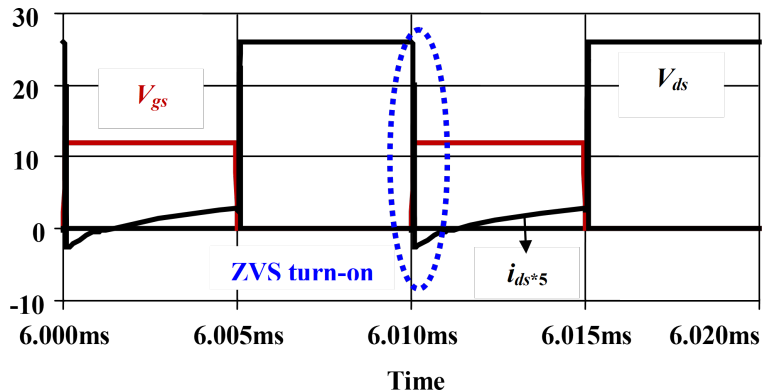

Figure 11: Simulation waveforms of gate-source voltage $\left(V_{g s}\right)$, drain-source voltage $\left(V_{d s}\right)$ and drain current $\left(i_{d}\right)$

which results in reduced switching losses. The output voltage and output current of proposed converter is depicted in fig. 12. From fig. 12 the output voltage obtained is $33.32 \mathrm{~V}$ and output current is $597 \mathrm{~mA}$, which meets the requirement of designed LED load. Further, the output waveforms are ripple free.
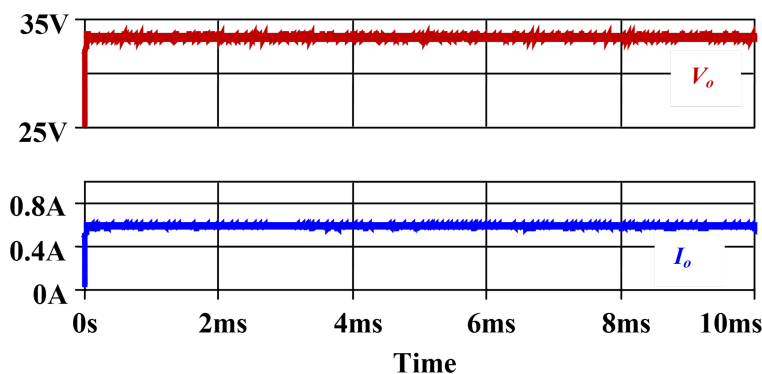

Figure 12: Simulation waveforms of output voltage $\left(V_{o}\right)$ and output current $\left(i_{0}\right)$ at $100 \%$ dimming.

In order to control the illumination, the dimming control is designed and tested with the proposed circuit. The dimming level, output voltage and output current of proposed converter at different dimming levels are illustrated in fig. 13 and fig. 14. Fig. 13 and fig. 14 clearly show that the peak current is constant and average current is controlling, varying the dimming level. Further by controlling the average current, illumination of load can be controlled.

The variation of of output power and capacitor voltage with dimming is illustrated in fig. 15 . From fig. 15, it can be concluded that output power increases along with $V_{c}$ with an increase in dimming. Efficiency versus dimming is plotted and illustrated in figure.16. From fig. 16 it is clear that the efficiency of the proposed converter is almost constant throughout the operation of dimming from $20 \%$ to $100 \%$. Further, the driver circuit achieved efficiency of $92.6 \%$ at $100 \%$ dimming. The major advantages of the proposed converter are reduced switching loss,
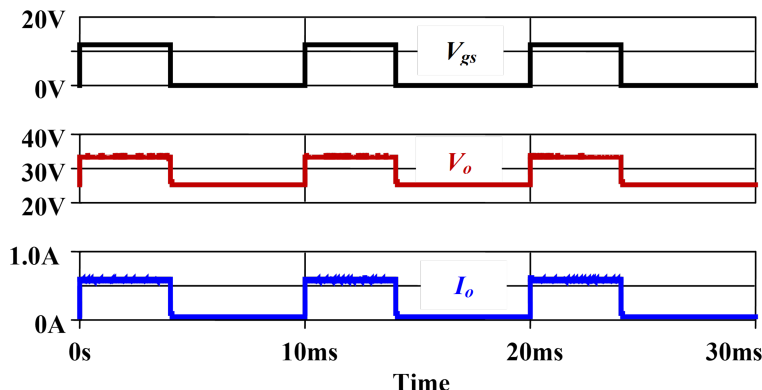

Figure 13: Simulation waveforms of output voltage and current at $40 \%$ dimming
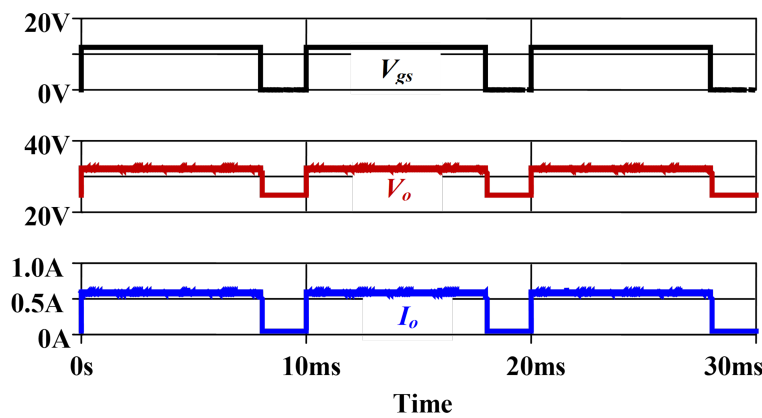

Figure 14: Simulation waveforms of output voltage and current at $40 \%$ dimming

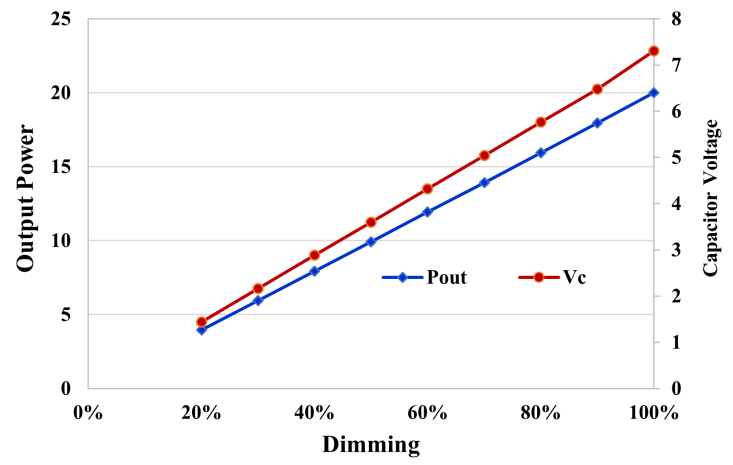

Figure 15: Variation of output power and capacitor voltage with dimming

high efficiency, reduced component count, and reduction of output electrolytic capacitor. Further, comparative study of the single input LC series resonant converter with similar works is summarized in Table 2. It can be noticed from Table 2 that the single input LC series resonant converter requires fewer switching devices. Also, the single input LC series resonant converter provides several advantages, such as dimming control, compact size, soft switching, and increased overall efficiency.

\section{CONCLUSION}


Table 2: Comparative study of proposed converter with other works in the literature

\begin{tabular}{c|c|c|c|c|c|c}
\hline & $\begin{array}{c}\text { U R } \\
\text { Reddy [2] }\end{array}$ & $\begin{array}{c}\text { C K R } \\
\text { Reddy [5] }\end{array}$ & $\begin{array}{c}\text { K B Park } \\
{[9]}\end{array}$ & $\begin{array}{c}\text { D Gacio } \\
{[15]}\end{array}$ & $\begin{array}{c}\text { M Saikia } \\
{[21]}\end{array}$ & $\begin{array}{c}\text { Proposed } \\
\text { converter }\end{array}$ \\
\hline \hline Method of & Hard & soft & soft & & soft & soft \\
switching & & 5 & 2 & 1 & 4 & 4 \\
MOSFETs & 4 & 5 & 2 & 8 & 4 & 2 \\
Diodes & 2 & 2 & 2 & 1 & 1 & 1 \\
Inductors & 3 & 3 & 4 & 2 & 2 & 2 \\
Capacitors & 2 & 15 & 10 & 12 & 10 & 8 \\
Component & 11 & 1 & 1 & 1 & 1 & 1 \\
Count & 1 & Yes & No & No & Yes & Yes \\
Output ports & No & & & & & \\
Dimming & & & & & \\
Control & 0.88 & 0.86 & 0.93 & 0.78 & 0.96 & 0.926 \\
Efficiency & \multicolumn{7}{l}{}
\end{tabular}

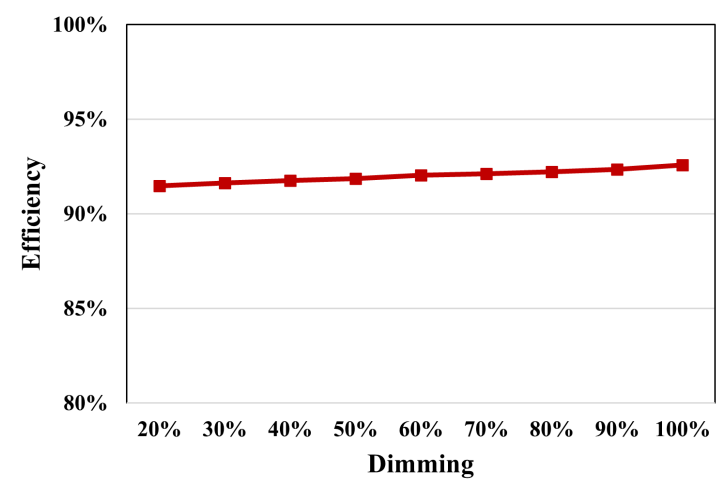

Figure 16: Efficiency vs Dimming level

This work proposes a single input full-bridge $L C$ series resonant converter based high brightness light emitting diode driver with ZVS. This work presents detailed analysis, design guidelines and simulation results in order to study the effectiveness of the proposed single input full-bridge series resonant converter. The proposed converter is designed to operate with zero-voltage-switching, resulting in reduction of switching losses. Owing to the reduction of switching losses, the overall efficiency of the proposed converter is $92.6 \%$ at $100 \%$ dimming. Further, since the converter is operated with DC bus voltage, the filter capacitor is sufficient to eliminate switching ripples, thereby resulting in the elimination of filter capacitors and an enhanced lifespan of the LED driver. Moreover, the proposed converter is tested with dimming levels from $20 \%$ to $100 \%$ to study the effectiveness of DPWM dimming control. For an input DC bus voltage of $24 \mathrm{~V}$, efficiency is higher than $92.6 \%$, achieved owing to less power processing by the converter and the presence of ZVS throughout the operating range. An efficient power factor correction converter may be included in the configuration and different con- trol techniques for better dimming may be studied in future work.

\section{References}

1.Peck, J., Ashburner, G., and Schratz, M. (2018) Solid state led lighting technology for hazardous environments, lowering total cost of ownership while improving safety, quality of light and reliability,. in Petroleum and Chemical Industry Conference Europe Conference Proceedings (PCIC EUROPE), pp. 1-8.

2.Reddy, U.R., and Raju, B.L.N. (2017) Single-stage electrolytic capacitor less non-inverting buck-boost pfc based ac-dc ripple free led driver,. IET Power Electronics, pp. 38-46, 10 (1).

3.Seenuansakulnee, P., and Phankong, N. (2018) An Application of Full-Bridge Converter for T8LED Lamp Dimming,. 15th International Conference on Electrical Engineering/Electronics, Computer, Telecommunications, and Information Technology (ECTI-CON), pp. 768-771.

4.Veeramallu, V.K.S., Porpandiselvi, S., and Narasimharaju, B.L. (2021) A Nonisolated Wide Input Series Resonant Converter for Automotive LED Lighting System,. IEEE Transactions on Power Electronics, pp. 5686-5699, 36 (5).

5.Reddy, C.K.R., selvi, S.P., and Veeramallu, V.K.S. (2018) Input Controlled Series Resonant Converter for LED Lighting Application,. 3rd International Conference on Communication and Electronics Systems (ICCES), pp. 608-612.

6.Ch, K.R., S, P., and N, V. (2019) An efficient full-bridge resonant converter for light emitting diode (LED) application with simple current control,. Int J Circ Theor Appl, pp. 2019- 2031,47. 
7.Ch, K.R., S, P., and N, V. (2019) A three-leg resonant converter for two output LED lighting application with independent control,. Int J Circ Theor Appl, pp. 1173-1187, 47.

8.Garcia, J., Calleja, A.J., Corominas, E.L., Gacio, D., and Campa, L. (2010) Low ripple interleaved converter for fast PWM dimming of power LEDs,. IEEE International Symposium on Industrial Electronics, pp. 915-920.

9.Park, K.-B., Kim, C.-E., Moon, G.-W., and Youn, M.-J. (2009) Non-isolated high step-up converter based on boost integrated half-bridge converter. 31st International Telecommunications Energy Conference, pp. 1-6.

10.Narasimharaju, B.L., Dubey, S.P., and Singh, S.P. (2012) Design and analysis of coupled inductor bidirectional DC-DC convertor for high-voltage diversity applications,. IET Power Electronics, pp. pp. 998-1007, 5 (7).

11.Reddy, U.R., and Narasimharaju, B.L. (2017) A Cost-Effective Zero-Voltage Switching Dual-Output LED Driver,. IEEE Transactions on Power ElectroniCs, pp. 7941-7953, 32 (10).

12. Broeck, H. van der, Sauerlander, G., and Wendt, M. (2017) Power driver topologies and control schemes for LEDs,. Twenty-Second Annual IEEE Applied Power Electronics Conference and Exposition, pp. 1319-1325.

13.U, R.R., and L, N.B. (2016) Improved efficiency coupled inductor-buck AC-DC light emitting diode (LED) driver. IEICE Electronics Express, pp. 1-6, 13 (16).

14.L, N.B., Gowtam, B., K, V.B., and Udumula, R.R. (2015) Modeling and analysis of voltage controlled positive output synchronous buck-boost converter,. Annual IEEE India Conference (INDICON), pp. 1-5.

15.Gacio, D., Alonso, J.M., Calleja, A.J., Garcia, J., and Rico-Secades, M. (2009) A Universal-Input Single-Stage High-Power-Factor Power Supply for HB-LEDs Based on Integrated Buck-Flyback Converter,. Twenty-Fourth Annual IEEE Applied Power Electronics Conference and Exposition, pp. 570-576.

16.Narasimharaju, B.L., Reddy, U.R., and Dogga, R. (2018) Design and analysis of voltage clamped bidirectional DC-DC converter for energy storage applications,. The Journal of Engineering, pp. 367-374, 2018 (7).

17.Narasimharaju, B.L., Prahlad, V.V., Reddy, U.R., Babu, K.V., and Srinivasan, P. (2014) Optimized dual active bridge Bi-directional DC-DC converter for UPS application,. IEEE International Conference on Power
Electronics Drives and Energy Systems (PEDES), pp. $1-6$.

18.U, R.R., and Narasimharaju, B.L. (2017) High step-down dual output light emitting diode driver,. International Journal of Renewable Energy Research, pp. 157-169, 7 (1).

19.Udumula, R.R., Hanumandla, D., and Ballapu, V. (2020) Closed Loop Voltage Mode Controlled High Step-Down/Step-Up Positive Output Buck-Boost Converter,. Journal of Power Technologies, pp. 255-262, 100(3).

20.Hwu, K.I., Yau, Y.T., and Lee, L.-L. (2009) Powering LED Using High-Efficiency SR Flyback Converter,. Twenty-Fourth Annual IEEE Applied Power Electronics Conference and Exposition, pp. 376-386.

21.Saikia, M., and Tom, B.M. (2016) LC series resonant converter based high power HBLED lamp driver with ZVS,. IEEE Annual India Conference (INDICON), pp. 1-6. 